\title{
ICT in Rural Development : Application and Challenges- A Review
}

\author{
Aditi Rajesh Nimodiya, Shruti Sunil Ajankar \\ B.E, Department of C.S.E, Jawaharlal Darda Institute of Engineering and Technology, Yavatmal, Maharashtra, \\ India
}

\section{Article Info}

Volume 8, Issue 6

Page Number : 464-472

\section{Publication Issue}

November-December-2021

\section{Article History}

Accepted : 15 Dec 2021

Published : 26 Dec 2021

\section{ABSTRACT}

ICT stands for Information and Communication Technology. ICT plays a vital role in developing the rural area in various sector, it has helped to develop the rural sector in tremendous way. It is used in rural area for the growth of various field like education, agriculture, medical treatment and many other. However due to lack of growth and awareness about ICT among the rural people the process of development is very less, still it has a tremendous impact in the growth of rural area. The rural people need to know the importance of ICT for the faster improvement of rural sector this will also help ICT to work more efficiently. This paper mainly focused the different application of ICT in various sector to improve the condition of rural area and the challenges faced by ICT to develop rural areas.

Keywords : ICT, Rural Area, Rural People, Rural Development, Application, Challenges

\section{INTRODUCTION}

Rural Development forms an important agenda of the Government [4]. Information and Communication Technologies (ICT) is being used by the government and non-government organization for developing the rural and urban areas [7]. ICT is one of the rapid development technological fields in the global society [3].

Rural policy nowadays is at the heart of the policy discussions in many countries all over the world, in the effort to address and effectively support the specific needs and opportunities of rural places and their population in the new era [11].

Rural areas in India still face challenges like sustainable employment in agriculture, allied sectors like quality education, marketing infrastructure, over exploitation of natural resources; inadequate electricity, transport, communication, health, food and storage facilities etc [10]. The rural ICT applications aim to present the services to citizens at their village access stepladder. The emergence of Information and Communications Technology (ICT) has provided means for faster and better 
communication, efficient storage, retrieval and processing of data and exchange and utilization of information to its users, be they individuals, groups, businesses, organizations or governments [5]. ICT offers an opportunity to introduce new activities, new services and applications into rural areas or to enhance existing services [4]. ICTs also serve as instrument of awareness creation and feedback giving rural people a voice in nation's socio-political life [1]. It contributes to qualitative and quantitative changes in rural life style [12].

Information and Communication Technology, if used properly can be of great advantage for the development at grass root levels. At the same time challenge remains with the administration to capture the minds of the rural masses, mostly illiterate, to make them adapt the new technology which is completely alien to them [13]. However, benefits of ICTs are not reached expected level in the rural areas still the rural population living with minimum level of ICTs facilities especially the poorest of the poor [3]. The main reason beside this is improper structure of ICT in rural area.

The integration of ICT and welfare schemes has resulted into latest buzz word called as "New India" or "Digital India" [10].

\section{Importance of Information and Communication Technology (ICT)}

There are different theories about why some countries are developed and some are not. Natural resources, colonialisms, and even having better geopolitical situations can't be the reasons for development because there are many developed countries without these supremacies. The only reason for the western countries to be developed in the last centuries is their improvement in advanced technology and science (Haj Fathaliha.1993). Information and communication technology (ICT), is one of the signs of technology. Today, ICT is one of the main technological and industrial improvement and progression signs. These days, we cannot ignore ICT since it has such a deep influence on political, social, cultural, and economical aspects of our lives. The influence of informatics technology is quite worthy to be studied both because it brings more opportunities to a society and more challenges into companies. It is obvious that the globalization of economy, culture, and many other modernization changes is not possible without information technology. The importance of information and its availability has changed the developed industrial societies into informatics societies. It also has changed their industrial economies into economies based on information and science [2].

\section{ICT and Livelihood:}

ICT has an impact on livelihood assets in a number of ways depending on the local context in which they are explained as [8]:

A. Human Capital: Improved access to education and training through distance learning Programs and Educational tools for wide range of formats.

B. Financial Capital: Support and strengthening of the local financial institutions including microcredit Organizations to improve information provision on services and facilities available such as loans and Savings schemes.

C. Social Capital: Improved 'networking' both at the community level with existing networks and Potentially amongst a much wider community.

\section{Application of ICT in Various Sector}

Information and Communication Technology has great relevance in today's world. If implemented properly ICT can surely bridge the gap between economically and technology backward and forward classes. With the IT boom in India technology is easily accessible to the government machineries with relevantly cheaper and convenient manner. Proper training and implementation of ICT programmes in 
simple way and language which is easily understandable by the rural people can surely bring about revolution in rural development [6].

Application of ICT in:
A. Agriculture
B. Health
C. Education
D. e-Governance
E. Economic Development
F. Employment
G. Climate Change

\section{A. Agriculture}

The large number of Majority of poor people lives in rural areas and derives their livelihoods directly or indirectly from agriculture [4]. The role of Information technology in agricultural sector is becoming more and more visible [6].

Increasing the efficiency, productivity and sustainability of small-scale farms is an area where ICT can make a significant contribution. Farming involves risks and uncertainties, with farmers facing many threats from poor soils, drought, erosion and pests. ICTs can deliver useful information to farmers about agriculture like crop care and animal husbandry, fertilizer and feedstock inputs, pest control, seed sourcing and market prices [4]. We use IT to convey and spread information to people on matters relevant to crop production and crop protection. The techniques of remote sensing using satellite technologies, geographical information systems, agronomy and soil sciences are used to increase the agricultural output. The availability of these kind of technologies can be ensured through efficacious internet tools and smart networks [6].

IT supports new methods for precision agriculture like computerized farm machinery that applies for fertilizers and pesticides. Farm animals are fed and monitored by electronic sensors and identification systems. Selling or buying online began to become popular in the world [6]. ICTs based applications can also facilitate electronic trading like where-tobuy/sell, when-to-buy/sell and how-to-buy/sell etc [10].

ICTs can help in extending research from lab to the field. Especially, FM, Community radio, mobile telephony, soil sensors and testing devices are most compelling for making Smart Farmers. Various ICTs based systems including touch screen kiosks, online Agri-clinics, mass/social media, Kisan Call Center, TV channels etc. can deliver useful information to farmers regarding crop care and animal husbandry, fertilizer and feedstock, drought mitigation, pest control, irrigation, weather forecasting, seed sources and market prices [10].

\section{B. Health}

Health care is one of the most promising areas for poverty alleviation [4]. ICTs can contribute to improve the coverage of national health services in rural areas [10].

Healthcare is important for [6]:

- Overall physical, social, and mental health status

- Prevention of disease

- Detection and treatment of illnesses

- Quality of life

- Preventable death

- Life expectancy

Health management requires the monitoring of the health status of the population, the provision of services as to the coverage and utility, drugs stocks and consumption patterns, equipment status and availability, Finances, personnel on a regular basis [6].

ICTs are being used in India to facilitate remote consultation, diagnosis and treatment. Delivering 
health care with ICTs enables health care professionals and institutions to address the critical medical needs of rural communities, especially those in remote locations and those that lack qualified medical personnel and services [4]. Telemedicine services can enable access to professional doctors (through web camera, VSAT etc.) irrespective of geographical location. Further, mobile/web applications on health care can help health workers to maintain mother/child database, communicate easily with district/regional health centers for prompt delivery of health services in rural areas [10].

For instance, to have good healthcare access, a rural resident must also have [6]:

- Financial means to pay for services, such as health insurance coverage that is accepted by the provider.

- Means to reach and use services, such as transportation to services which may be located at a distance, and the ability to take paid time off of work to use such services.

- Confidence in their ability to communicate with healthcare providers, particularly if the patient is not fluent in English or has poor health literacy.

- Confidence in their ability to use services without compromising privacy.

- Confidence in the quality of the care that they will receive.

\section{Education}

ICT is an effective mechanism to make tremendous change and advancement in traditional education scenario [10]. The use of ICTs in education aims to improve the quality of teaching and learning as well as democratize the access to education [4].

The economics of production of digital media and use of digital services, with very low marginal costs, allow significant scaling up. In countries like India, development of appropriate educational materials (which can involve high fixed costs) can also be achieved economically, if target markets are defined and created by overcoming the relatively high fixed costs of obtaining access to IT resources. Rural ICT operators can provide such educational services at low cost, as part of an overall array of services [6].

Now days, students are attracted more towards econtents in the form of multimedia presentations and animations. With the launch of online courses and availability on e-study material of most of the education boards and universities, rural people can also have opportunity to avail best educational facilities regardless of geographical distance and limited financial resources [10]. Moreover, appropriate use of ICTs in the classroom fosters critical, integrative and contextual teaching and learning; develops information literacy (the ability to locate, evaluate and use information). Thus, it improves the overall efficiency of the delivery of education in schools and educational management institutions at the national, state/provincial and community level [4].

There are rural deficits in all the key components of education - teachers, textbooks and interaction digital material and ICT based interactions can ameliorate some of these deficits. Even more importantly, the use of ICTs allows for interactive, visually appealing content that appears to greatly enhance student interest, learning and retention [6].

\section{D. e-Governance}

The poverty can be adequately addressed by effective use of e-governance and ICT application in environmental management. Improved governance by using ICT can have direct impact in reducing poverty and improving the environment [4]. Through ICTs all Government services can be accessible to common man in his locality, through common service delivery outlets [10]. 
ICT can contribute in a large way in making government processes more efficient and transparent by encouraging communication and information sharing among rural and marginalized people [4]. The Information and Communication Technologies (ICT) are being increasingly used by the governments to deliver its services at the locations convenient to the citizens. The rural ICT applications attempt to offer the services of central agencies (like district administration, cooperative union, and state and central government departments) to the citizens at their village door steps. These applications utilize the ICT in offering improved and affordable connectivity and processing solutions. Computerization of land records have been a great success in application of ICT in rural development. Land records are great importance to contemporary socio-economic imperatives and their revision and updation are necessary for capturing the changes in rural social dynamics. Land records are an important part of rural development [6].

The govt. of India started the centrally sponsored scheme of Computerization of Land Records (CoLR) in 1988-89 with main objectives of [6]:

- Creating database of basic records

- Facilitating the issues of copies of records

- Reducing work load by elimination of drudgery of paper work

- Minimizing the possibilities manipulation of land records, and

- Creating a land management information system. The farmers were largely benefited CoLR. The farmers can get all necessary records when they need it, these records are free from human arbitrations, the updating becomes easy, free from harassment and the farmers had direct access to information regarding their property

\section{E. Economic Development}

Information and Communication Technology has a vital role in connecting the rural community to outside world for exchange of information, a basic necessity for economic development. Effective use of ICT can demolish geographical boundaries and can bring rural communities closer to global economic systems and be of meaningful help to the underprivileged [4].

\section{F. Employment}

Employment ICT can create rural employment, particularly for young people who have some educational qualifications, but not enough to compete effectively for jobs in cities. Alternatively, such individuals may be constrained from moving by high search costs, or, in the case of women, social constraints. ICT have been demonstrated to provide attractive job opportunities for such people, particularly young women. In addition to direct income and employment generation (which might be relatively small), field interviews suggest that the confidence of these young people is boosted tremendously, and they provide attractive role models for others in rural areas who might consider nontraditional, non-farm rural employment possibilities.

Employment ICT can create rural employment, particularly for young people who have some educational qualifications, but not enough to compete effectively for jobs in cities. Alternatively, such individuals may be constrained from moving by high search costs, or, in the case of women, social constraints. ICT have been demonstrated to provide attractive job opportunities for such people, particularly young women. In addition to direct income and employment generation (which might be relatively small), field interviews suggest that the confidence of these young people is boosted tremendously, and they provide attractive role models for others in rural areas who might consider non- 
traditional, non-farm rural employment possibilities. The transaction costs for obtaining jobs in India are extremely high, and the Internet and IT in general provide efficiencies in advertising jobs by employers, searching by job seekers, and initial screening of applications. The costs for job seekers in villages and small towns have been particularly high, and the ability to overcome distance barriers through convenient Internet access has been a significant benefit, according to some of the organizations implementing rural ICT in India [6].

\section{G. Climate Change}

The role of ICTs under climate change situation can be explored based on the linkages that exist between ICTs as a system component and its ability to withstand \& its ability to recover and to change under changing climatic conditions [4].

Using ICTs, climatology and agronomics, latest information on weather/climate change can be given to farmers. ICTs can handle massive data produced at different spatiotemporal scales by various sensors observing earth/environment in order to extract useful climate change information and patterns. Further, for natural resources, ICTs like RS, GIS etc. can be applied for scientific planning, management and monitoring [10].

ICTs can help strengthen the physical preparedness of livelihood systems for climate change related events through applications such as geographic information systems (GIS), and positioning and modelling applications. ICTs can also strengthen institutions and organisations needed for the system to withstand the occurrence of climatic events, including the support of social networks and the facilitation of coordinated action [4].

ICTs can enable swift access and mobilisation of financial assets, particularly through applications for mobile banking and mobile finance. By enabling rapid access to financial capital and transactions, ICTs have the potential not only to strengthen local livelihoods but also to improve the speed and efficiency with which local communities are able to cope with and adapt to climate change related hazards and events. ICTs can also speed up access to information. This is particularly important when an acute climate related shock such as landslide or flood occurs. Mobile based telecommunications networks allow rapid communication of information, thus improving the speed of disaster warning, response and recovery. ICTs can enable access to the set of resources in the event of climate change related shocks or disturbances. [4].

\section{CHALLENGES FACED BY ICT IN RURAL DEVELOPMENT}

Rural areas are still underserved in terms of ICTs infrastructure and capacity building. As a result, ICTs have not been able to play their expected role in the development of rural areas [10].

Some of the challenges faced by ICT are:

1. Illiteracy: Illiteracy is a massive problem of people from the rural areas [9]. Literacy rate is considerably low in rural areas as compare to urban areas. The condition is more unsatisfactory when we talk about the Digital Literacy [10].

2. Language Dominance: The dominance of English on the internet bounds access of non-Englishspeaking Population. In the case of India, mostly population does speak in Hindi [1].

3. Language barrier: The information accessible on web is in English as it is an overall acknowledged International language [9]. In Rural Area English is not well known to people properly which cause a barrier for them to understand it. 
4. Connectivity: Connectivity is not available in most rural areas. Major power cut in rural zone. Even though uninterrupted power supply systems are used yet they demonstrate inadequate to cope up with the power breakdowns [9]. The limited supply of electricity restrains rural areas to fully utilize ICTs applications especially at village level [10]. ICT does not include only the Internet but a range of other devices which could be used individually or in convergence with each other. There ought to be a significant improvement in the connectivity [9]. Further, unavailability of quality UPS and Generator Set as well as their maintenance at village level is also a major issue [10].

5. Infrastructure: There is acute shortage of required infrastructure like electricity, internet technology and methods of communications will influence the speed which postponed the implementation process [1]. The primary point is the huge investment expected to build up a solid system with infrastructure [9].

6. Poverty: In India most of the people are living under poverty condition and does great efforts for their daily living. To them accessing the internet is a costly issue for necessary communications in the form of installing the required telephone lines needed for internet or email access is similarly too exclusive in developing country [1].

7. Professionals Scarcity: Acute shortage of project leaders and guides who could ensure implementation of the ICTs at the grass root levels [9]. At village level, few digitally literate people are available. If villagers (especially farmers, youth, and beneficiaries) are willing to utilize ICTs based applications then who will regularly train them to acquire the desired knowledge and skills is a major concern [10].
8. Acceptance in Rural People: Apart from other factors, user acceptance for the ICTs applications in the rural areas is a major challenge it is often taken for granted that any technology transfer to the rural areas would be accepted but we have to consider their own established cultural and traditional ways of doing things [10].

9. Unethical Use of ICTs: In the era of digital world, personal privacy, data security, copyright infringement, computer crimes, cyber-crime etc are also coming in front as major concerns. Further, unethical use of social media is also posing problems [10].

\section{CONCLUSION}

1. As the conclusion of this paper, we can say that ICT is the key factor for rural development. The awareness of ICT can increase the interest of people belong to rural areas [7].

2. Information Technology indirectly impacted the rural economy and helping in rural development which is major issue for developing countries like India. Analyses show that effective applications and channels have been used to benefit rural economy. However, it is important that the government should take more efforts to use of ICT in its development programmes. People of rural areas should be educated to use ICT effectively and efficiently [1].

3. In order to have a stronger relationship between ICT and rural economy following points can be suggested [1]:

a) ICT should be used in such a way that it can improve the quality of life of rural people and can give more opportunities for employment creation. Thus, ICT in rural areas should be employment oriented. 
b) ICT should be used in such a way that this brings transparency and accountability in various Economical and social programs of government.

c) There is a need to assess the needs of the rural people with regard to information technology i.e. linkage between demand and purpose of these services and product.

d) Government should implement poverty eradication programmes so that rural people can take benefit of ICT facilities which they are deprived due to their poverty condition.

e) Rural peoples must be educated so that they can become literate and accept the benefits of technology

4. The use of ICT tools helps in strengthening social networks, empowerment and participation, as well as fostering productive processes at the local level through the provision of employment and skills, as well as support services for micro-enterprise activities. In rural communities of developing countries, with limited capacities and resources to respond to the effects of extreme natural hazards, drought, landslides, floods, and to the impacts of these events on local social systems (e.g. health, infrastructure, transportation, migration), ICT tools (the potential of telecentres for disaster preparedness and response) are emerging as an area of increasing interest [4].

5. The country should recognize the potential ICT has for their communities residing in rural areas. The policies, schemes etc. should be equipped with the ICTs enabled plan to avail the benefits of latest technologies [10].

\section{REFERENCES}

[1]. ICT IN RURAL DEVELOPMENT OF INDIA by Sunita in 4th International Conference on "Recent Research Development in
Environment, Social Sciences and Humanities" (IETE) Institution of Electronics and Telecommunication Engineers, Chandigarh, India 26th November 2017, ISBN: 978-9386171-82-5

[2]. The Challenges of ICT Development in Rural Area Case study: Village Aleni, Meshkin Shahr in Ardebil Province by Bahram Imani, Ahmad Hajalizadeh, Ali Jahangiri, Masoud Heydarvand, Kamelia Eftekhar ardebili, Esmaeel Ebrahimi in Australian Journal of Basic and Applied Sciences, 6(9): 674-682, 2012, ISSN 1991-8178

[3]. ICT -Enabled Rural Education in India by Niraj Kumar Roy in International Journal of Information and Education Technology, Vol. 2, No. 5, October 2012

[4]. Role of ICTs in rural development with reference to changing climatic conditions by Abhay Kumar and K. M. Singh ICAR Research Complex for Eastern Region, Patna

[5]. ICT for Rural Development: Opportunities and Challenges by Ankita Gupta and Dr. S.S. Gautam in International Journal of Information \& Computation Technology, ISSN 0974-2239 Volume 7, Number 1 (2017), pp. 13-23, (C) International Research Publications House

[6]. The Role of ICT in Rural Development by A.Vignesh, M.Sasikumar, S.Devi in International Journal of Scientific Research in Computer Science Applications and Management Studies, ISSN 2319 - 1953

[7]. Information and Communication Technology for Rural Development by Ankur Mani Tripathi, Abhishek Kumar Singh, Arvind Kumar in International Journal on Computer Science and Engineering (IJCSE)

[8]. Information and Communication Technology in Indian Rural Development Program with EGovernance by Dr. Sandeep Singh, Anand Prakash Rawal in International Journal of Engineering Research \& Technology (IJERT), ISSN: 2278-0181, Published by, www.ijert.org, 
ISNCESR-2015 Conference Proceedings, Special Issue - 2015

[9]. ICT based initiatives for Rural Development in India by Raffan Ali and Dr.Shyna Saif in Journal of Emerging Technologies and Innovative Research (JETIR), (C) 2020 JETIR October 2020, Volume 7, Issue 10, www.jetir.org (ISSN-2349-5162)

[10]. (The Gist of Kurukshetra) Role Of ICTs In Rural Development [MAY- 2018]

[11]. ICT Needs and Implementation for Rural Development-A Review by Shruti Sunil Ajankar, Aditi Rajesh Nimodiya in International Multidisciplinary E- Conference On Contribution of Various Aspects In Nation Building In Association with International Journal of Scientific Research in Science and Technology, Volume 9, Issue 5, Print ISSN: 2395-6011, Online ISSN: 2395-602X (www.ijsrst.com)

[12]. UNIT 6 ROLE OF ICT IN RURAL DEVELOPMENT

[13]. APPLICATION OF ICT IN RURAL DEVELOPMENT: OPPORTUNITIES AND CHALLENGES by Sushmita Mukherjee in Students' Research, Global Media Journal Indian Edition/ISSN 2249-5835, Winter Issue / December 2011, Vol. 2/No.2

\section{Cite this article as :}

Aditi Rajesh Nimodiya, Shruti Sunil Ajankar, "ICT in Rural Development : Application and Challenges - A Review", International Journal of Scientific Research in Science and Technology (IJSRST), Online ISSN : 2395-602X, Print ISSN : 2395-6011, Volume 8 Issue 6, pp. 464-472, November-December 2021. Available at doi : https://doi.org/10.32628/IJSRST218664

Journal URL : https://ijsrst.com/IJSRST218664 